\title{
Stress Analysis of Osteoporotic Lumbar Vertebra Using Finite Element Model with Microscaled Beam-Shell Trabecular-Cortical Structure
}

\author{
Yoon Hyuk Kim, ${ }^{1}$ Mengying Wu, ${ }^{1}$ and Kyungsoo $\mathrm{Kim}^{2}$ \\ ${ }^{1}$ Department of Mechanical Engineering, Kyung Hee University, 1 Seocheon-dong, Giheung-gu, \\ Yongin-si, Gyeonggi-do 446-701, Republic of Korea \\ ${ }^{2}$ Department of Applied Mathematics, Kyung Hee University, 1 Seocheon-dong, Giheung-gu, Yongin-si, \\ Gyeonggi-do 446-701, Republic of Korea \\ Correspondence should be addressed to Yoon Hyuk Kim; yoonhkim@khu.ac.kr
}

Received 8 March 2013; Accepted 18 April 2013

Academic Editor: Chang-Hwan Im

Copyright (C) 2013 Yoon Hyuk Kim et al. This is an open access article distributed under the Creative Commons Attribution License, which permits unrestricted use, distribution, and reproduction in any medium, provided the original work is properly cited.

\begin{abstract}
Osteoporosis is a disease in which low bone mass and microarchitectural deterioration of bone tissue lead to enhanced bone fragility and susceptibility to fracture. Due to the complex anatomy of the vertebral body, the difficulties associated with obtaining bones for in vitro experiments, and the limitations on the control of the experimental parameters, finite element models have been developed to analyze the biomechanical properties of the vertebral body. We developed finite element models of the L2 vertebra, which consisted of the endplates, the trabecular lattice, and the cortical shell, for three age-related grades (young, middle, and old) of osteoporosis. The compressive strength and stiffness results revealed that we had developed a valid model that was consistent with the results of previous experimental and computational studies. The von-Mises stress, which was assumed to predict the risk of a burst fracture, was also determined for the three age groups. The results showed that the von-Mises stress was substantially higher under relatively high levels of compressive loading, which suggests that patients with osteoporosis should be cautious of fracture risk even during daily activities.
\end{abstract}

\section{Introduction}

Osteoporosis is a disease in which low bone mass and microarchitectural deterioration of bone tissue lead to enhanced bone fragility and susceptibility to fracture [1]. Osteoporosis is one of the most common health problems affecting both men and women [2], and it is becoming increasingly prevalent in our aging society [3]. The degree of osteoporosis is categorized with the T-score, which is the number of standard deviations above or below that of an average young adult: normal, above -1.0 ; osteopenia, above -2.5 and below -1.0; osteoporosis, below -2.5 ; severe osteoporosis, the presence of one or more fragility facture $[4,5]$. About 1.5 million fractures due to osteoporosis are reported annually in the United States, including over 700,000 vertebral fractures [6]. Spine fractures in particular result in a high mortality rate: survival is $72 \%$ in the first year and only $28 \%$ after five years [7].
The human spine is composed of 24 spinal bones, called vertebrae, which are stacked on top of one another to create the spinal column. The spinal column is the body's main upright support and the vertebral bone is the primary compressive load-bearing structure in the spine [8]. The vertebral bone is composed of a porous internal trabecular bone core surrounded by a thin shell of cortex. In osteoporosis, bone mineral density is reduced even in the outer layer, so the cortex is thinner than in normal bones. The structure of osteoporotic trabecular bone is similar to a lattice, while normal bone is plate like.

Due to the complex anatomy of the vertebral body, the difficulties associated with obtaining bones for in vitro experiments, and the limitations on the control of the experimental parameters, finite element models have been developed to analyze the biomechanical properties of the vertebral body $[9,10]$. Large-scale voxel-based models have been used to investigate the mechanics of bone, where the trabecular 


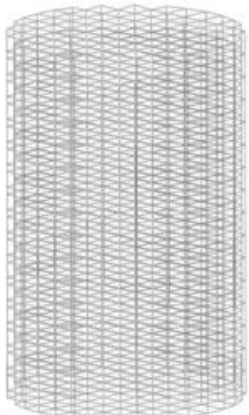

Young

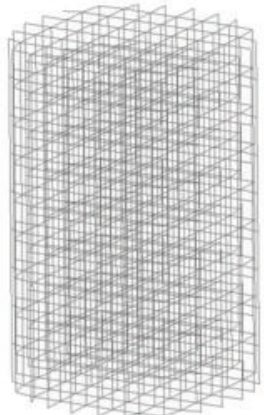

Middle

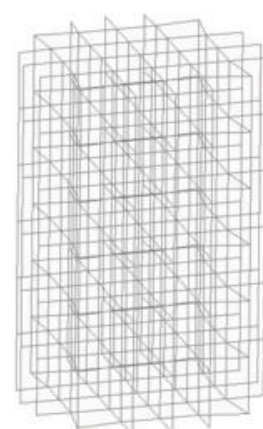

Old

(a) Before perturbation

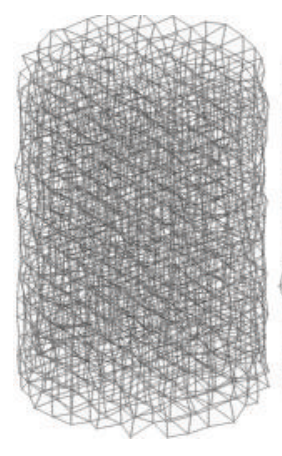

Young

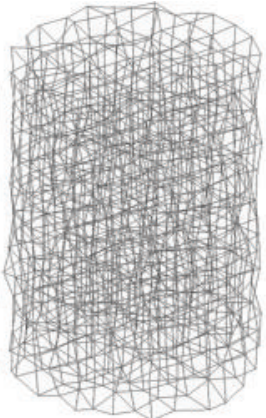

Middle

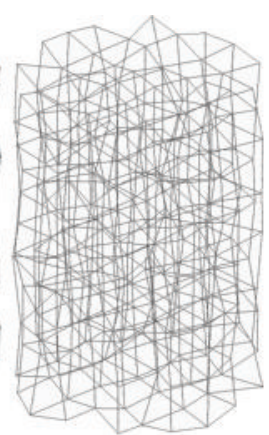

Old

(b) After perturbation

FIGURE 1: Lattice models with a trabecular structure before and after perturbation for three age groups-young $(<50$ years); middle (50 through 75 years); and old (>75 years).

structure is modeled as a solid body with material properties obtained from previous experiments [11-13]. While the trabecular structure from three-dimensional microcomputed tomography $(\mu \mathrm{CT})$ was directly implemented into a finite element using the cubic voxel meshes, an additional surface smoothing process was necessary [14]. Lattice models have been proposed to simulate osteoporotic and normal bone through variation in trabecular thickness, spacing, or random material removal [15-19]. Since these studies only addressed the trabecular structure within a small region, a more recent study combined the lattice beam element model of the trabecular core with a thin layer of shell elements for the cortical part to make a whole vertebra model, and analyzed compressive strength, compressive stiffness, and tissue-level strain [20]. In this paper, finite element models of normal and various grades of osteoporotic lumbar vertebrae that incorporate the microscaled trabecular structure of lattice models and the cortical area of shell elements were developed. The models were validated using the results of previous experimental and computational studies. The von-Mises stress was analyzed to predict the risk of the burst fracture in osteoporotic bones of various grades.

\section{Materials and Methods}

Trabecular bone was modeled as a lattice composed of many struts, including both vertical (longitudinal) and horizontal (transverse) struts. A single strut model was developed with two quadratic beam elements. By combining single strut models, we were able to develop a cylindrical core lattice model for different age groups: young $(<50$ years), middle (50 through 75 years), and old ( $>75$ years) (Figure 1(a)). The geometries, which were the horizontal and vertical thicknesses $\left(d_{h}\right.$ and $\left.d_{v}\right)$ and the horizontal and vertical lengths $\left(l_{h}\right.$ and $\left.l_{v}\right)$ of each strut, are provided for each age group in Table 1 based on [20,21]. The elastic-perfectly plastic material properties of the struts were based on those of a previous study [20], in which Young's modulus was $8.0 \mathrm{GPa}$, the Poisson ratio was 0.3 , and the yield stress was $64 \mathrm{MPa}$. In order to mimic the irregular structure of the trabecular
TABLE 1: Geometries for trabecular lattice models for the young, middle, and old groups.

\begin{tabular}{lcccc}
\hline & \multicolumn{2}{c}{$\begin{array}{c}\text { Thickness of a single } \\
\text { strut }(\mathrm{mm})\end{array}$} & $\begin{array}{c}\text { Length of a single strut } \\
(\mathrm{mm})\end{array}$ \\
& $\begin{array}{c}\text { Horizontal } \\
\left(d_{h}\right)\end{array}$ & $\begin{array}{c}\text { Vertical } \\
\left(d_{v}\right)\end{array}$ & $\begin{array}{c}\text { Horizontal } \\
\left(l_{h}\right)\end{array}$ & $\begin{array}{c}\text { Vertical } \\
\left(l_{v}\right)\end{array}$ \\
\hline Young & 0.150 & 0.208 & 0.674 & 0.633 \\
Middle & 0.116 & 0.187 & 0.861 & 1.100 \\
Old & 0.107 & 0.201 & 1.145 & 1.668 \\
\hline
\end{tabular}

struts, the lattice models were perturbed by randomly moving vertex nodes with MATLAB (MathWorks Inc., MA, USA) (Figure 1(b)) [20,22]. The distance that each vertex node was moved ranged between $0 \%$ and $30 \%$ of trabecular spacing (horizontal length $l_{h}$ and vertical length $l_{v}$ ) according to a Gaussian distribution. The Gaussian distribution $\mathrm{N}(\mu, \sigma)$ was given based on the assumption that the mean $\mu=0$ and the random values are between $-3 \sigma$ and $3 \sigma$ with the probability of $99.7 \%$. Since the movement was constrained up to $30 \%$ of trabecular spacing, the standard deviation $\sigma$ was supposed as $\sigma=(1 / 3) \times 0.3 \times\left(\left(l_{h}+l_{v}\right) / 2\right)=\left(l_{h}+l_{v}\right) / 20$. The direction was also randomly generated to prevent the model from having a bias in one direction.

The trabecular bone lattice models were validated by comparing the results for compressive strength $F_{c}$, which is the capacity of a material or structure to withstand axial forces, with those in the experimental study [21]. The geometry of the specimen (cylindrical shape, height of $10 \mathrm{~mm}$, and radius of $3.5 \mathrm{~mm}$ ), the boundary conditions, and the loading conditions were selected based on the experimental study [21]. The bottom nodes of the lattice model were fixed, and the total reaction force on all fixed bottom nodes in the axial direction was calculated until the top nodes were displaced by $2 \mathrm{~mm}$ downward in the axial direction, which was regarded as being compressed, using the ABAQUS/Standard (Dassault Systèmes, RI, USA). The maximum value of reaction force during the compression was considered as the compressive strength $F_{c}$. 


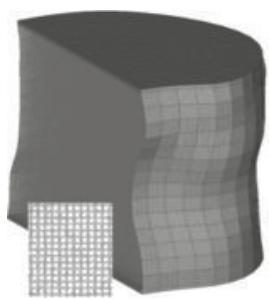

Young

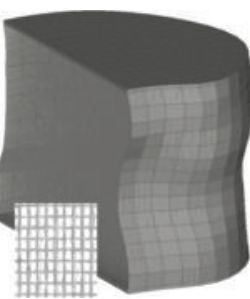

Middle

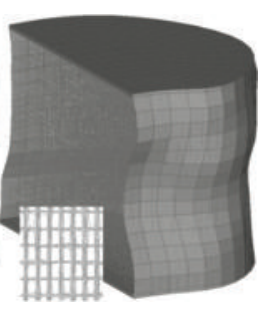

Old
Figure 2: Vertebral body models in the three age groups-young ( $<50$ years); middle (50 through 75 years); and old ( $>75$ years).

Computed tomography (CT) images of a $1 \mathrm{~mm}$ slice were obtained from L2 of a male subject with a height of $175 \mathrm{~cm}$. Based on these CT images, two endplates and the cortical part of the vertebra were developed (Figure 2). The elements of the S4 type and the C3D8 type composed the cortical shell and the solid endplates. The thickness of the endplates was $0.5 \mathrm{~mm}$ for all age groups, while the thickness of the cortical shell was $0.5 \mathrm{~mm}$ for the young and middle groups and $0.2 \mathrm{~mm}$ for the old group based on the results of a previous study [20]. The material properties of the endplates and the cortical shell were also based on the results of a previous study [20], in which Young's modulus was $8.0 \mathrm{GPa}$, the Poisson ratio was 0.3 , and the yield stress was $64 \mathrm{MPa}$. The trabecular lattice was tied with the cortical shell and endplates by fixing the ends of trabecular beam elements on the interfaces of the cortical shell and endplate for all translational and rotational degrees of freedom. In this case, the posterior element of the vertebra was not considered because the whole vertebral body has too many elements, and the posterior element plays only a minor role during compressive loading [23].

The nodes on the bottom side of the bottom endplate were fixed, and the nodes of the top side of the upper endplate were controlled by a reference point. The reference point was displaced $6 \mathrm{~mm}$ downward in the axial direction. The compressive strength $F_{c}$ which was the maximum total reaction force on the bottom endplate in the axial direction during the compression up to $6 \mathrm{~mm}$ was calculated using the ABAQUS/Standard (Dassault Systèmes, RI, USA). In addition, the compressive stiffness $k_{c}$ was estimated as $k_{c}=$ $F_{c} / \delta_{c}$, where $\delta_{c}$ was the corresponding axial downward displacement of the reference point at the maximum compressive strength. The compressive strength $F_{c}$ and stiffness $k_{c}$ were compared with those from previous experimental and computational studies [20,24-27] for the validation of the model.

The von-Mises stress in the trabecular lattice was then analyzed for the three age groups (young, middle, and old) under compressive loading. Since the intradiscal pressure in upright standing is around $0.5 \mathrm{MPa}$ and the intradiscal pressure is 1.5 times the average pressure over the endplate, the pressure on the endplate was considered to be $0.3 \mathrm{MPa}$ in upright standing [28-30]. Thus, the compressive loading on the entire upper endplate was assumed to be $0.15 \mathrm{MPa}, 0.3 \mathrm{MPa}, 0.45 \mathrm{MPa}, 0.6 \mathrm{MPa}$, and $0.75 \mathrm{MPa}$. The ABAQUS/Explicit (Dassault Systèmes, RI, USA) was used for the analysis.

\section{Results and Discussion}

In order to mimic a realistic trabecular structure, we developed a model in which perturbation of the vertex nodes occurred within $30 \%$ of the trabecular spacing according to a Gaussian distribution $\mathrm{N}(\mu, \sigma)$, where the mean $\mu$ was $0 \mathrm{~mm}$ in all age groups and the standard deviation $\sigma$ was $0.065 \mathrm{~mm}$ in the young group, $0.098 \mathrm{~mm}$ in the middle group, and $0.141 \mathrm{~mm}$ in the old group. We used a perturbation factor of $30 \%$ because Silva and Gibson showed that cross-sectional images of a model with $30 \%$ perturbation were comparable to those of specimens [21]. The mechanical anisotropy was also included in the model due to the discrepancy in horizontal and vertical geometries of trabecular lattice models. Therefore, we developed a model with an anisotropic irregular trabecular structure, and this model can be regarded as clinically relevant.

The compressive strength $F_{c}$ of the trabecular bone lattice model was $1.74 \mathrm{MPa}$ for the middle group, while it was $1.35 \pm 0.64 \mathrm{MPa}$ in [22]. For the whole-body model, the compressive strength $F_{c}$ was $7.35 \mathrm{kN}$ for the young group, $3.80 \mathrm{kN}$ for the middle group, and $1.36 \mathrm{kN}$ for the old group. In a previous computational study with the same age classes, the compressive strength was $5.74 \mathrm{kN}$ for the young group, $4.06 \mathrm{kN}$ for the middle group, and $1.25 \mathrm{kN}$ for the old group [20]. In experimental studies using normal vertebrae, the compressive strengths have ranged from 0.9 to $15.9 \mathrm{kN}$ ( 0.9 to $5.0 \mathrm{kN}$ in [24], 1.5 to $4.5 \mathrm{kN}$ in [25], 2.0 to $8.0 \mathrm{kN}$ in [26], and 2.0 to $15.9 \mathrm{kN}$ in [27]). In addition, the compressive stiffness $k_{c}$ was $5.6 \mathrm{kN} / \mathrm{mm}$ for the young group, $15.8 \mathrm{kN} / \mathrm{mm}$ for the middle group, and $29.4 \mathrm{kN} / \mathrm{mm}$ for the old group, respectively. In a previous computational study, the compressive stiffness was $8.0 \mathrm{kN} / \mathrm{mm}$ for the young group, $18.7 \mathrm{kN} / \mathrm{mm}$ for the middle group, and $29.4 \mathrm{kN} / \mathrm{mm}$ for the old group [20]. These results indicate that the presented model could be considered as being validated for the compression.

The highest von-Mises stresses occurred in the middle of the trabecular region (Figure 3). The maximum stress was strongly related to age: maximum values were about $50 \%$ higher for the middle group than the young group and about $120 \%$ higher for the old group than the young age group (Figures 4 and 5). In addition, the maximum stress was greater than $50 \%$ of the yield stress $(64 \mathrm{MPa})$ when compressive loading exceeded $0.45 \mathrm{MPa}$ for middle group and $0.3 \mathrm{MPa}$ for the old group; in contrast, the maximum stress did not reach $50 \%$ of the yield stress even under $0.75 \mathrm{MPa}$ for the young group. The $0.45 \mathrm{MPa}$ of compressive loading on the endplate equates to about $0.7 \mathrm{MPa}$ of intradiscal pressure, which is similar to that produced during daily activities, such as standing while bent forward (1.10 MPa), standing up from a chair $(1.10 \mathrm{MPa})$, and lifting or holding a weight of $20 \mathrm{~kg}$ $(1.10-2.30 \mathrm{MPa})$ [30]. These results suggest that osteoporosis can affect the stress acting on the vertebra even during routine daily activities.

The vertebra model that incorporates a realistic trabecular structure is advantageous because it permits the simulation of in vivo specimens for the study of osteoporosis. The microscale trabecular structure represented by tiny struts would provide the mechanism that the strut deformation or 


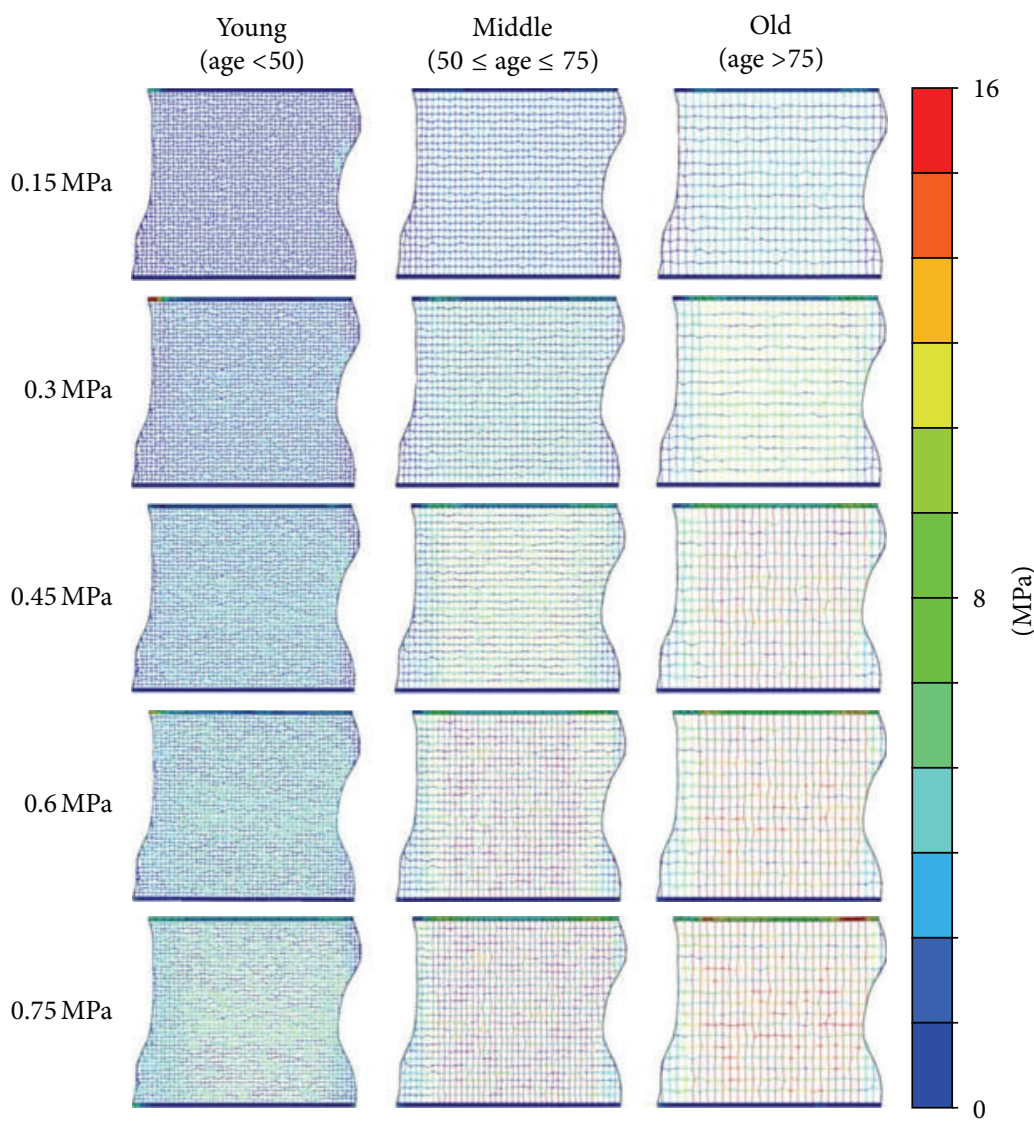

Figure 3: Cross-sectional view in the middle sagittal plane of the von-Mises stress distribution for the three age groups under $0.15 \mathrm{MPa}$, $0.3 \mathrm{MPa}, 0.45 \mathrm{MPa}, 0.6 \mathrm{MPa}$, and $0.75 \mathrm{MPa}$ of compressive loading.

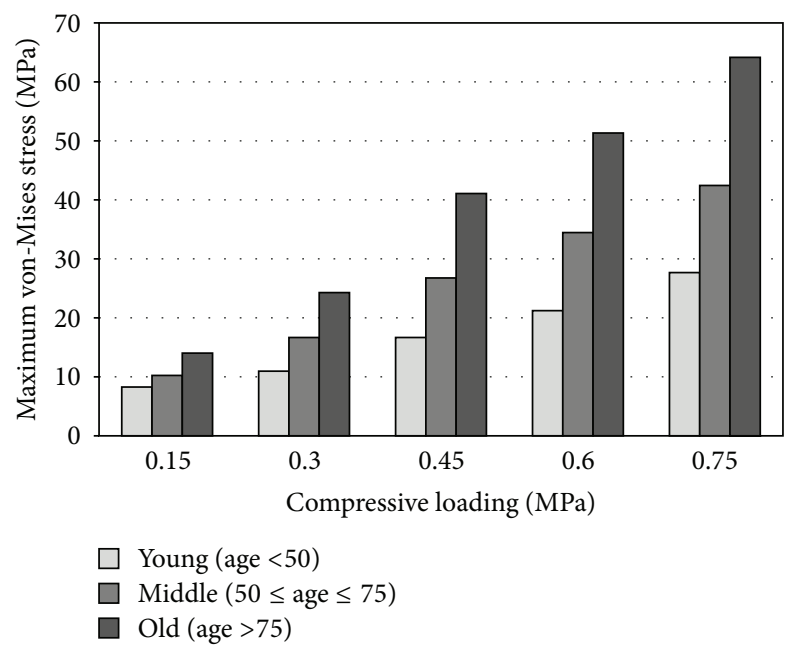

FIgURE 4: Maximum stress for the three age groups under $0.15 \mathrm{MPa}$, $0.3 \mathrm{MPa}, 0.45 \mathrm{MPa}, 0.6 \mathrm{MPa}$, and $0.75 \mathrm{MPa}$ of compressive loading.

buckling leads to the fracture in a whole vertebra. In addition, various grades of osteoporosis can be incorporated into the model by changing the spacing between the struts.

This study has some limitations. The validity of models was indirectly confirmed by comparing the compressive

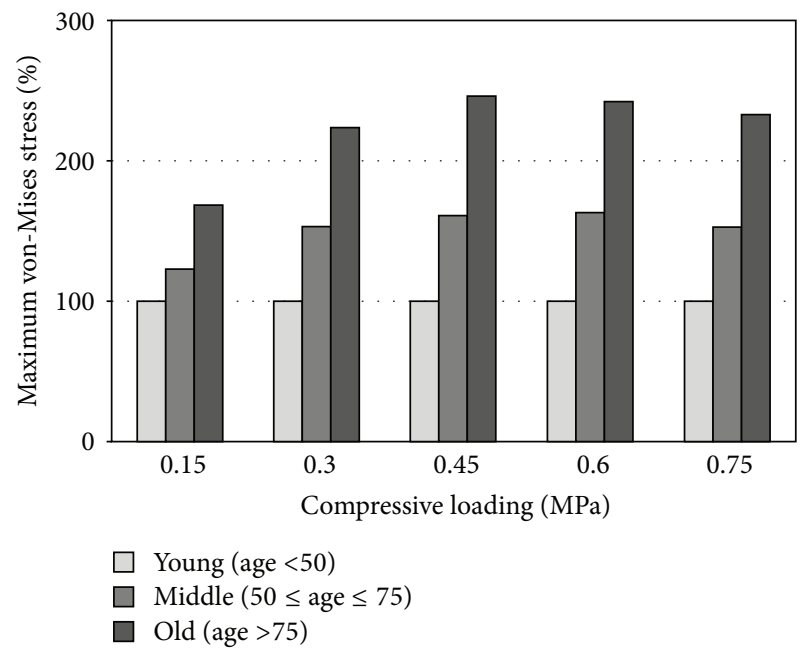

FIgURE 5: Ratios of the maximum stress for the middle and old groups relative to the young group under $0.15 \mathrm{MPa}, 0.3 \mathrm{MPa}$, $0.45 \mathrm{MPa}, 0.6 \mathrm{MPa}$, and $0.75 \mathrm{MPa}$ of compressive loading.

strength and compressive stiffness of the developed models to those in the previous experimental and computational studies. The full validation of the model through experiments with the same specimen from which the model was generated can enhanced the confidence of this study. In addition, the 
generic lattice model was randomly perturbed, and the thicknesses of the endplates and the cortical shell were assumed to be uniform for all age groups. Patient-specific information on the microstructure and geometry of the bone using data from CT scans would improve the accuracy and relevance of the stress analysis. Finally, the quantitative relationship between the von-Mises stress and the fracture risk was not investigated. Mechanical tests that measure the stress and failure strength of bone, as well as clinical observations that accurately identify the region of the fracture site, would improve the prediction of vertebral fracture in osteoporotic patients.

\section{Conclusions}

Osteoporosis is a major contributor to the increased risk of fracture with age due to low bone mass and structural change. We developed finite element models of the L2 vertebra, which consisted of the endplates, the trabecular lattice, and the cortical shell, for three age-related grades of osteoporosis. The compressive strength and stiffness results revealed that we had developed a valid model that was consistent with the results of previous experimental and computational studies. The von-Mises stress, which was assumed to predict the risk of a burst fracture, was also determined for the three age groups. The results showed that the von-Mises stress was substantially higher under relatively high levels of compressive loading, which suggests that patients with osteoporosis should be cautious of fracture risk even during daily activities.

\section{Conflict of Interests}

All authors, Yoon Hyuk Kim, Mengying Wu, and Kyungsoo Kim, disclose that there are no financial nor personal relationships with other people or organizations that could inappropriately influence (bias) this work.

\section{Acknowledgments}

This work was supported by Basic Science Research Program through the National Research Foundation of Korea (NRF) funded by the Ministry of Education, Science and Technology (2010-0005167) and 2013 National Agenda Project (NAP) funded by Korea Research Council of Fundamental Science \& Technology (NAP-09-2/P-13-JC-LU01-C01).

\section{References}

[1] W. A. Peck, P. Burckhardt, C. Christiansen et al., "Consensus development conference: diagnosis, prophylaxis, and treatment of osteoporosis," American Journal of Medicine, vol. 94, no. 6, pp. 646-650, 1993.

[2] B. L. Riggs and L. J. Melton III, "The worldwide problem of osteoporosis: insights afforded by epidemiology," Bone, vol. 17, no. 5, pp. 505S-511S, 1995.

[3] J. T. Lin and J. M. Lane, "Osteoporosis: a review," Clinical Orthopaedics and Related Research, no. 425, pp. 126-134, 2004.

[4] J. A. Kanis, "Assessment of fracture risk and its application to screening for postmenopausal osteoporosis: synopsis of a WHO report," Osteoporosis International, vol. 4, no. 6, pp. 368-381, 1994.

[5] J. A. Kanis, E. V. McCloskey, H. Johansson, A. Oden, L. J. Melton III, and N. Khaltaev, "A reference standard for the description of osteoporosis," Bone, vol. 42, no. 3, pp. 467-475, 2008.

[6] S. R. Cummings, D. Bates, and D. M. Black, "Clinical use of bone densitometry: scientific review," Journal of the American Medical Association, vol. 288, no. 15, pp. 1889-1897, 2002.

[7] J. A. Kanis, L. J. Melton III, C. Christiansen, C. C. Johnston, and N. Khaltaev, "The diagnosis of osteoporosis," Journal of Bone and Mineral Research, vol. 9, pp. 1137-1141, 1994.

[8] W. C. Hutton, B. M. Cyron, and J. R. R. Stott, "The compressive strength of lumbar vertebrae," Journal of Anatomy, vol. 129, no. 4, pp. 753-758, 1979.

[9] U. Wolfram, L. O. Schwen, U. Simon, M. Rumpf, and H. J. Wilke, "Statistical osteoporosis models using composite finite elements: a parameter study," Journal of Biomechanics, vol. 42, no. 13, pp. 2205-2209, 2009.

[10] V. Kosmopoulos and T. S. Keller, "Finite element modeling of trabecular bone damage," Computer Methods in Biomechanics and Biomedical Engineering, vol. 6, no. 3, pp. 209-216, 2003.

[11] R. Müller, T. Hildebrand, and P. Rüegsegger, "Non-invasive bone biopsy: a new method to analysis and display the threedimensional structure of trabecular bone," Physics in Medicine and Biology, vol. 39, pp. 145-164, 1994.

[12] W. M. Park, Y. S. Park, K. Kim, and Y. H. Kim, "Biomechanical comparison of instrumentation techniques in treatment of thoracolumbar burst fractures: a finite element analysis," Journal of Orthopaedic Science, vol. 14, no. 4, pp. 443-449, 2009.

[13] P. K. Zysset, M. S. Ominsky, and S. A. Goldstein, "A novel 3D microstructural model for trabecular bone: the relationship between fabric and elasticity," Computer Methods in Biomechanics and Biomedical Engineering, vol. 1, pp. 321-331, 1998.

[14] P. Arbenz and C. Flaig, "On smoothing surfaces in voxel based finite element analysis of trabecular bone," Lecture Notes in Computer Science, vol. 4818, pp. 69-77, 2008.

[15] O. C. Yeh and T. M. Keaveny, "Biomechanical effects of intraspecimen variations in trabecular architecture: a threedimensional finite element study," Bone, vol. 25, no. 2, pp. 223 228, 1999.

[16] X. E. Guo and C. H. Kim, "Mechanical consequence of trabecular bone loss and its treatment: a three-dimensional model simulation," Bone, vol. 30, no. 2, pp. 404-411, 2002.

[17] D. Dagan, M. Be'ery, and A. Gefen, "Single-trabecula building block for large-scale finite element models of cancellous bone," Medical and Biological Engineering and Computing, vol. 42, no. 4, pp. 549-556, 2004.

[18] I. Diamant, R. Shahar, and A. Gefen, "How to select the elastic modulus for cancellous bone in patient-specific continuum models of the spine," Medical and Biological Engineering and Computing, vol. 43, no. 4, pp. 465-472, 2005.

[19] I. Diamant, R. Shahar, Y. Masharawi, and A. Gefen, "A method for patient-specific evaluation of vertebral cancellous bone strength: in vitro validation," Clinical Biomechanics, vol. 22, no. 3, pp. 282-291, 2007.

[20] K. McDonald, J. Little, M. Pearcy, and C. Adam, "Development of a multi-scale finite element model of the osteoporotic lumbar vertebral body for the investigation of apparent level vertebra mechanics and micro-level trabecular mechanics," Medical Engineering and Physics, vol. 32, no. 6, pp. 653-661, 2010. 
[21] M. J. Silva and L. J. Gibson, "Modeling the mechanical behavior of vertebral trabecular bone: effects of age-related changes in microstructure," Bone, vol. 21, no. 2, pp. 191-199, 1997.

[22] L. Mosekilde, "Sex differences in age-related loss of vertebral trabecular bone mass and structure-biomechanical consequences," Bone, vol. 10, no. 6, pp. 425-432, 1989.

[23] M. Hongo, E. Abe, Y. Shimada, H. Murai, N. Ishikawa, and K. Sato, "Surface strain distribution on thoracic and lumbar vertebrae under axial compression: the role in burst fractures," Spine, vol. 24, no. 12, pp. 1197-1202, 1999.

[24] E. M. Lochmüller, F. Eckstein, D. Kaiser et al., "Prediction of vertebral failure loads from spinal and femoral dual-energy $\mathrm{x}$ ray absorptiometry, and calcaneal ultrasound: an in situ analysis with intact soft tissues," Bone, vol. 23, no. 5, pp. 417-424, 1998.

[25] K. Imai, I. Ohnishi, M. Bessho, and K. Nakamura, "Nonlinear finite element model predicts vertebral bone strength and fracture site," Spine, vol. 31, no. 16, pp. 1789-1794, 2006.

[26] R. P. Crawford and T. M. Keaveny, "Relationship between axial and bending behaviors of the human thoracolumbar vertebra," Spine, vol. 29, no. 20, pp. 2248-2255, 2004.

[27] D. L. Kopperdahl, J. L. Pearlman, and T. M. Keaveny, "Biomechanical consequences of an isolated overload on the human vertebral body," Journal of Orthopaedic Research, vol. 18, no. 5, pp. 685-690, 2000.

[28] F. Magerl, M. Aebi, S. D. Gertzbein, J. Harms, and S. Nazarian, "A comprehensive classification of thoracic and lumbar injuries," European Spine Journal, vol. 3, no. 4, pp. 184-201, 1994.

[29] A. Nachemson and J. M. Morris, "In vivo measurements of intradiscal pressure. discometry, a method for the determination of pressure in the lower lumbar discs," The Journal of Bone and Joint Surgery, vol. 46, pp. 1077-1092, 1964.

[30] H. J. Wilke, P. Neef, M. Caimi, T. Hoogland, and L. E. Claes, "New in vivo measurements of pressures in the intervertebral disc in daily life," Spine, vol. 24, no. 8, pp. 755-762, 1999. 


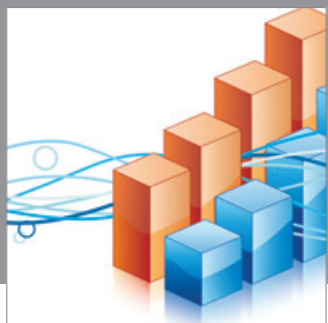

Advances in

Operations Research

mansans

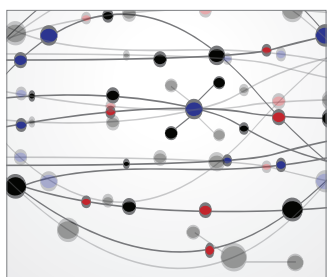

The Scientific World Journal
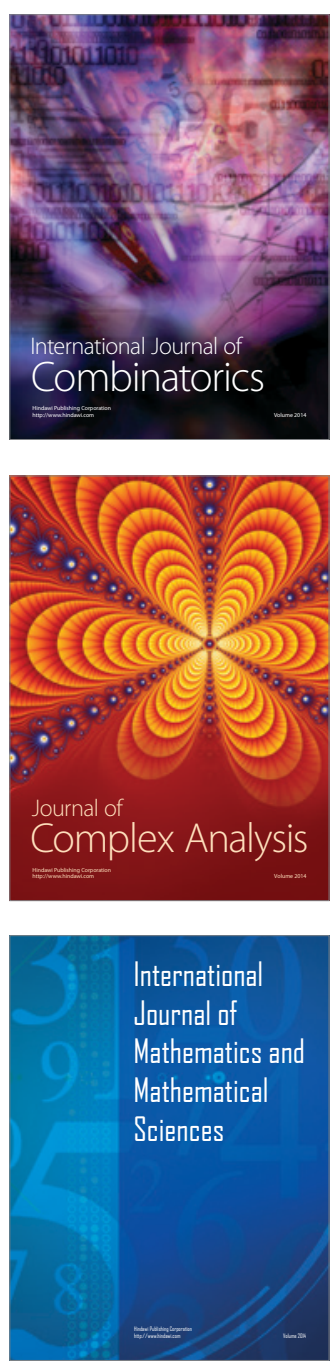
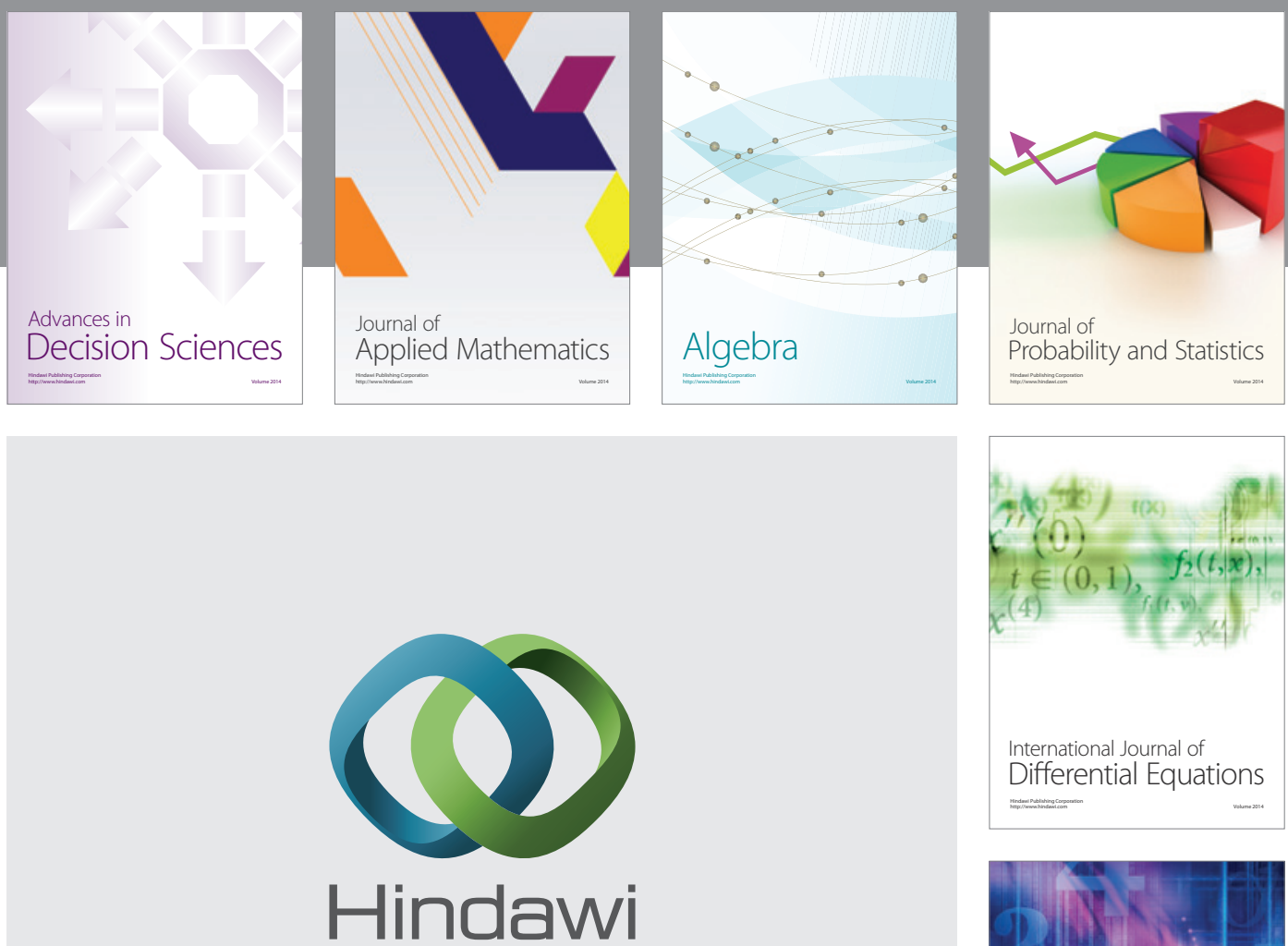

Submit your manuscripts at http://www.hindawi.com
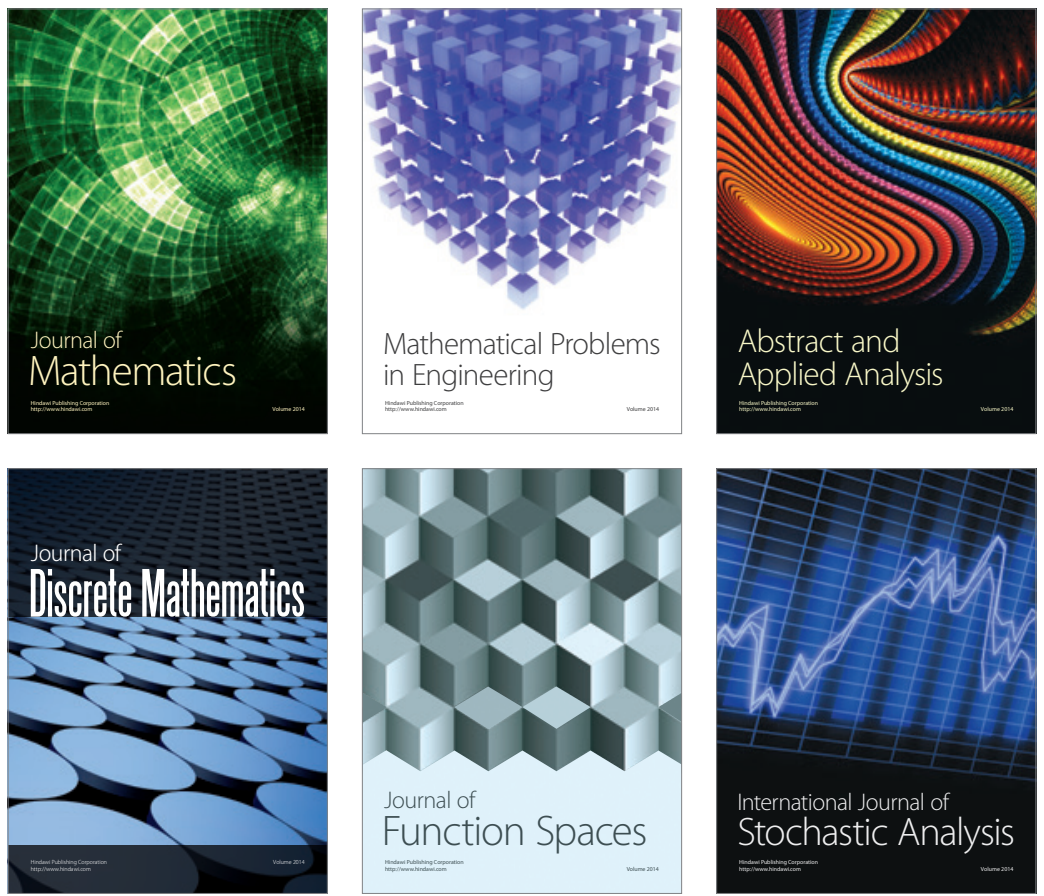

Journal of

Function Spaces

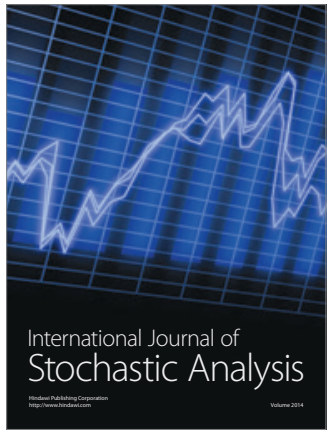

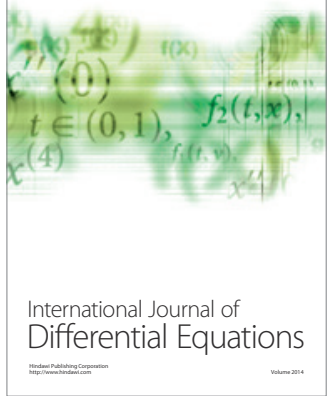
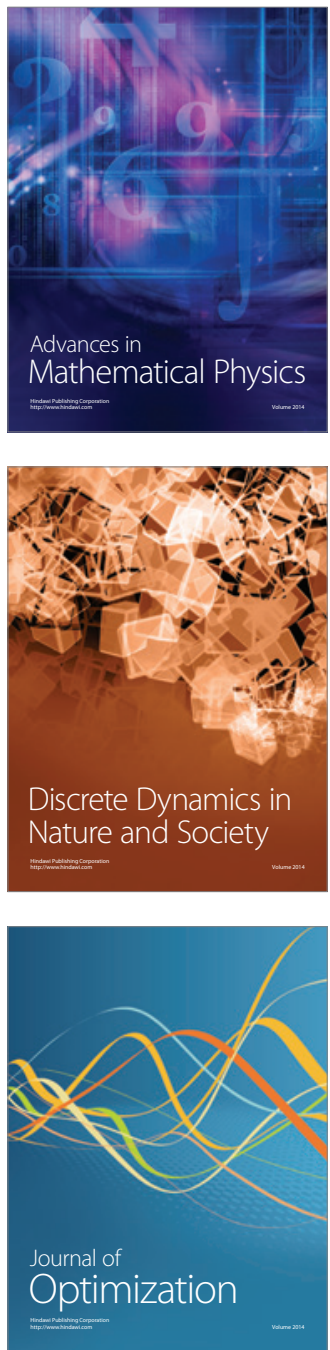